\title{
Bile duct injury after laparoscopic cholecystectomy: the value of endoscopic retrograde cholangiopancreatography
} P H P Davids, J Ringers, E A J Rauws, L Th de Wit, K Huibregtse, M N van der Heyde,
G N J Tytgat
Laparoscopic cholecystectomy has become the most popular method for removing the gall bladder. ${ }^{12}$ Early data suggested that the incidence of bile duct injury, which is 1 in 1000 after open cholecystectomy, ${ }^{+6}$ might be 1 in 100 after laparoscopic cholecystectomy. ${ }^{37}$ Recent reports, however, show that the incidence may decrease to $0.3-0.5 \%$ as experience increases. ${ }^{289}$

Postoperative bile leakage and benign bile duct stricturing after open cholecystectomy can be diagnosed safely and effectively with endoscopic retrograde cholangiopancreatography (ERCP).${ }^{10}$ Subsequent endoscopic management can be successful in most cases. ${ }^{11-16}$ It has not yet been well defined whether a similar approach is justified for bile duct injury after laparoscopic cholecystectomy. Therefore, we evaluated the role of diagnostic and therapeutic endoscopy in a consecutive series of patients referred to our gastroenterology department with bile duct injury after laparoscopic cholecystectomy.

\section{Patients and methods}

Between May 1991 and June 1992, 12 patients (nine women) were referred for ERCP from different hospitals, because of suspicion of bile duct injury after laparoscopic removal of the gall bladder. Table I summarises the clinical features of these patients. Visualisation of the biliary tree was performed by standard ERCP, with sedation by midazolam given intravenously. ${ }^{17}$

Our technique and results of endoscopic treatment of bile duct injury after open cholecystectomy have been described in detail elsewhere. ${ }^{1316}$ In essence our policy is as follows (Table II): when bile duct leakage is present, we prefer to decompress the biliary tree through endoscopic sphincterotomy, often followed by short term (4-6 weeks) insertion of a biliary endoprosthesis. When stricturing is present, dilation is attempted by longterm stenting, preferably with

TABLE II Amsterdam treatment protocol for postoperative bile duct injury

\begin{tabular}{ll}
\hline Cholangiography & Treatment strategy \\
\hline Total stop & Proximal HJ \\
Leakage & ES \\
Cystic duct stump & ES \\
Hepatic radical & EBS \\
Common bile duct & EBS \\
Hepatic duct & EBS \\
Large defect & ES and stone extraction \\
Stone & EBS \\
Stricture & EBS \\
Leakage and stricture & \\
\hline
\end{tabular}

$\mathrm{HJ}=$ hepaticojejunostomy with Roux-en-Y loop; EBS = endoscopic biliary stenting; $\mathrm{ES}=$ endoscopic sphincterotomy.

Proximal HJ

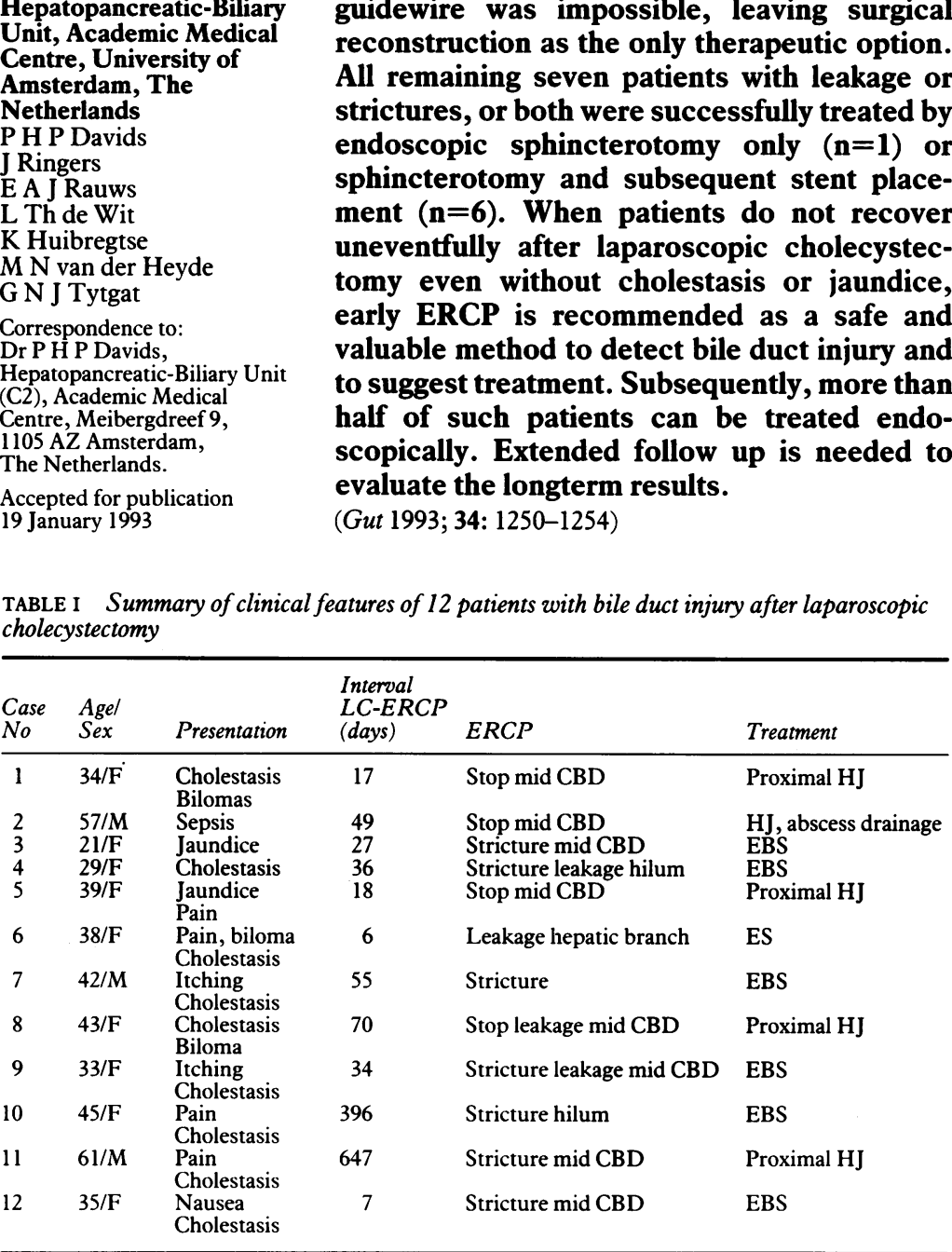

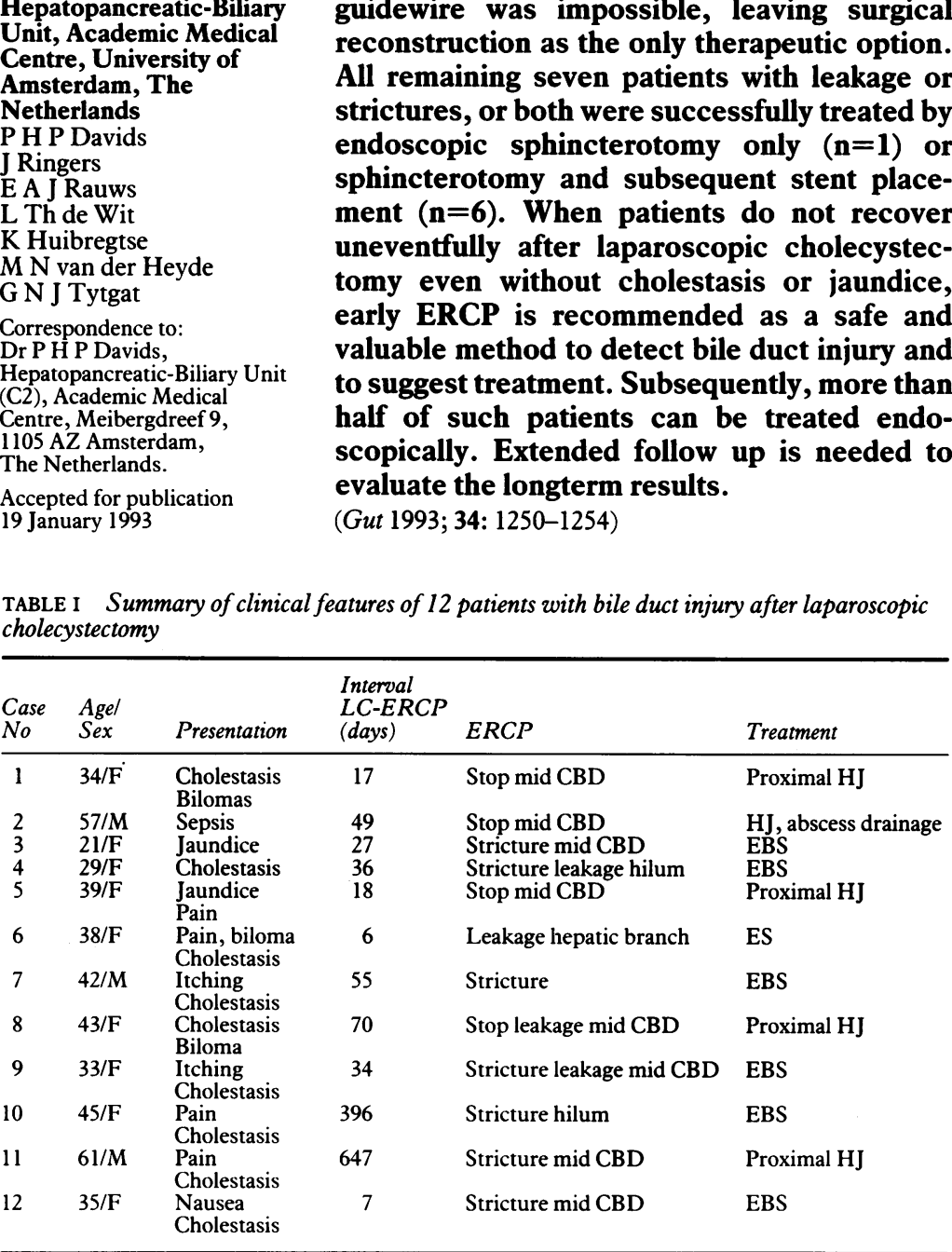

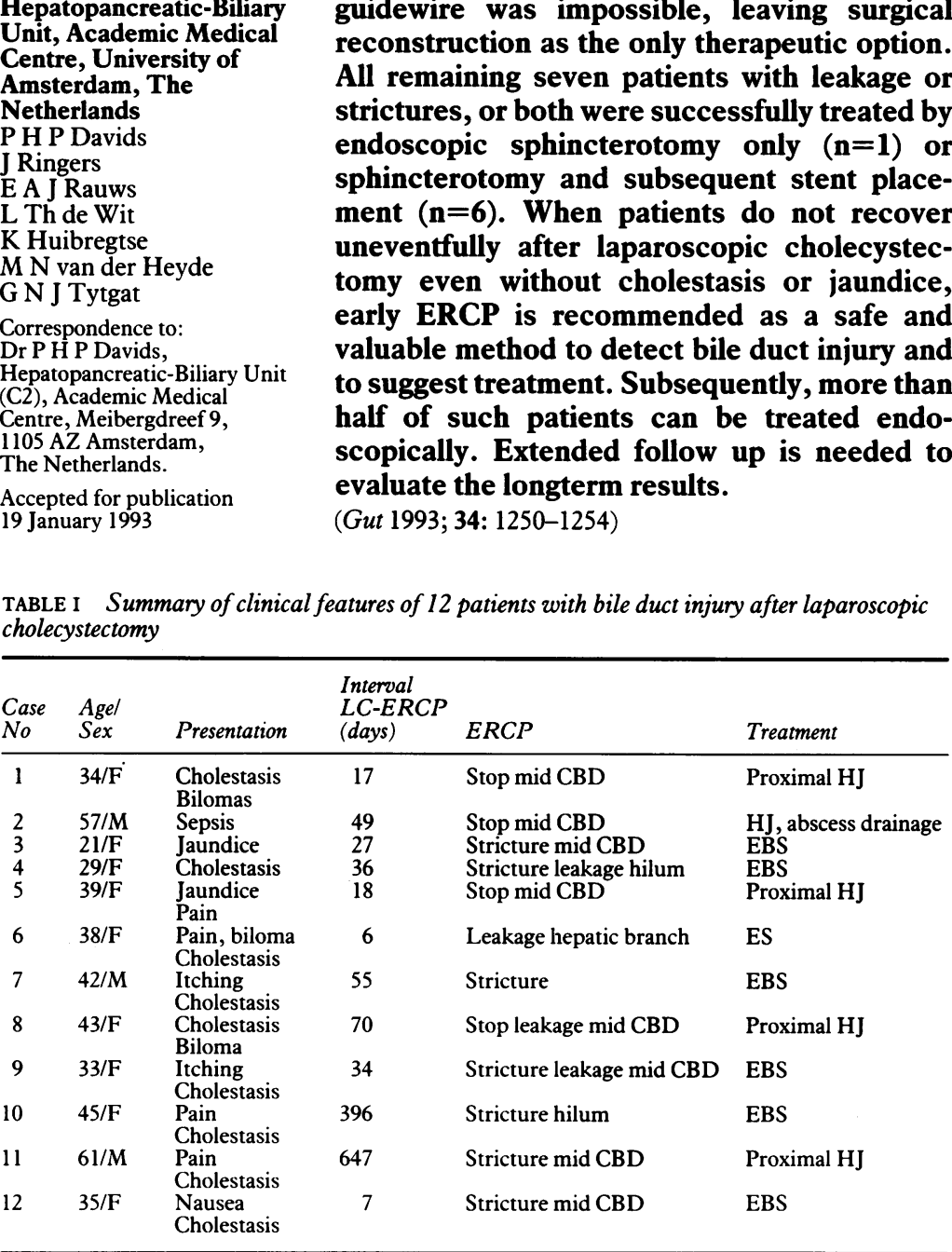

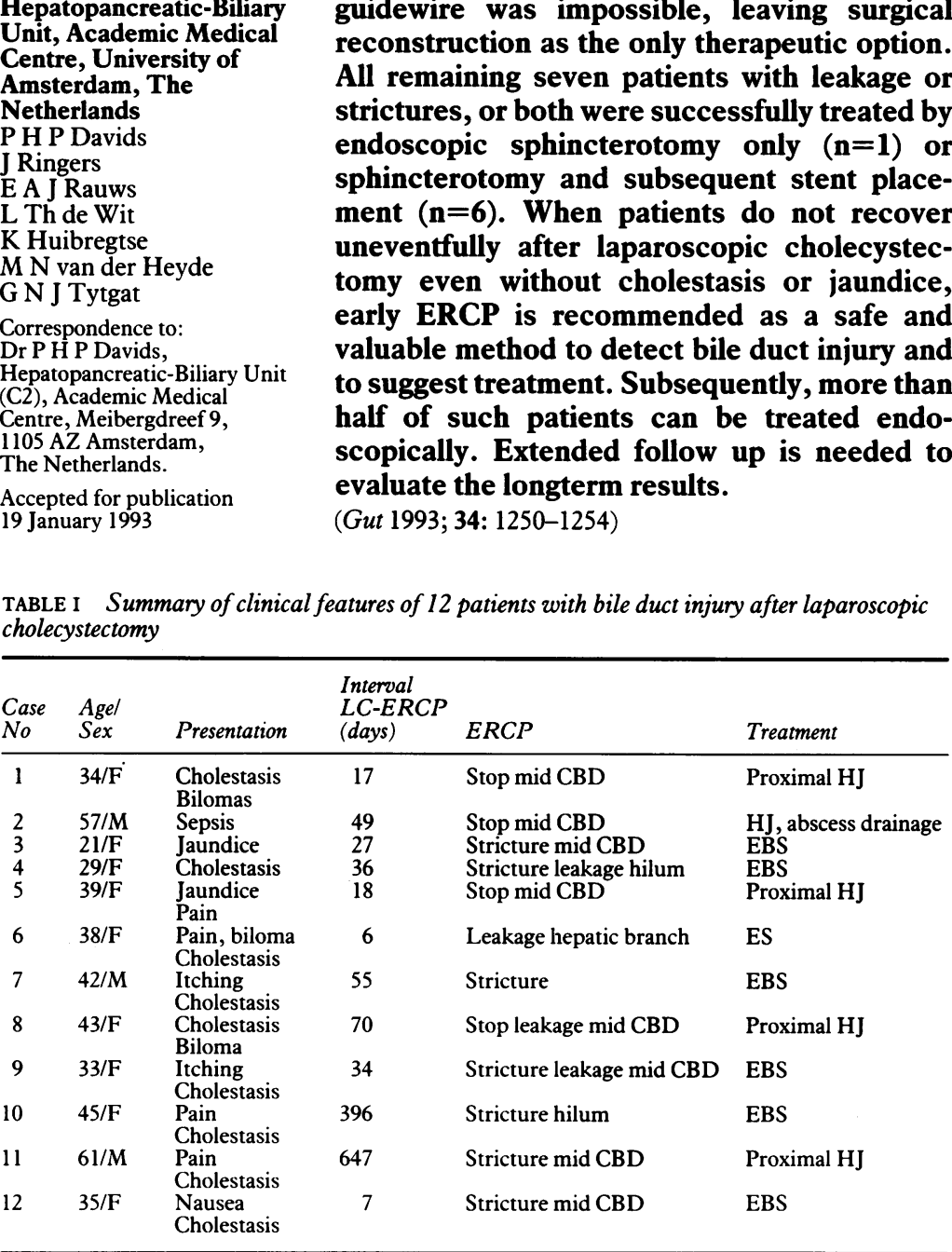

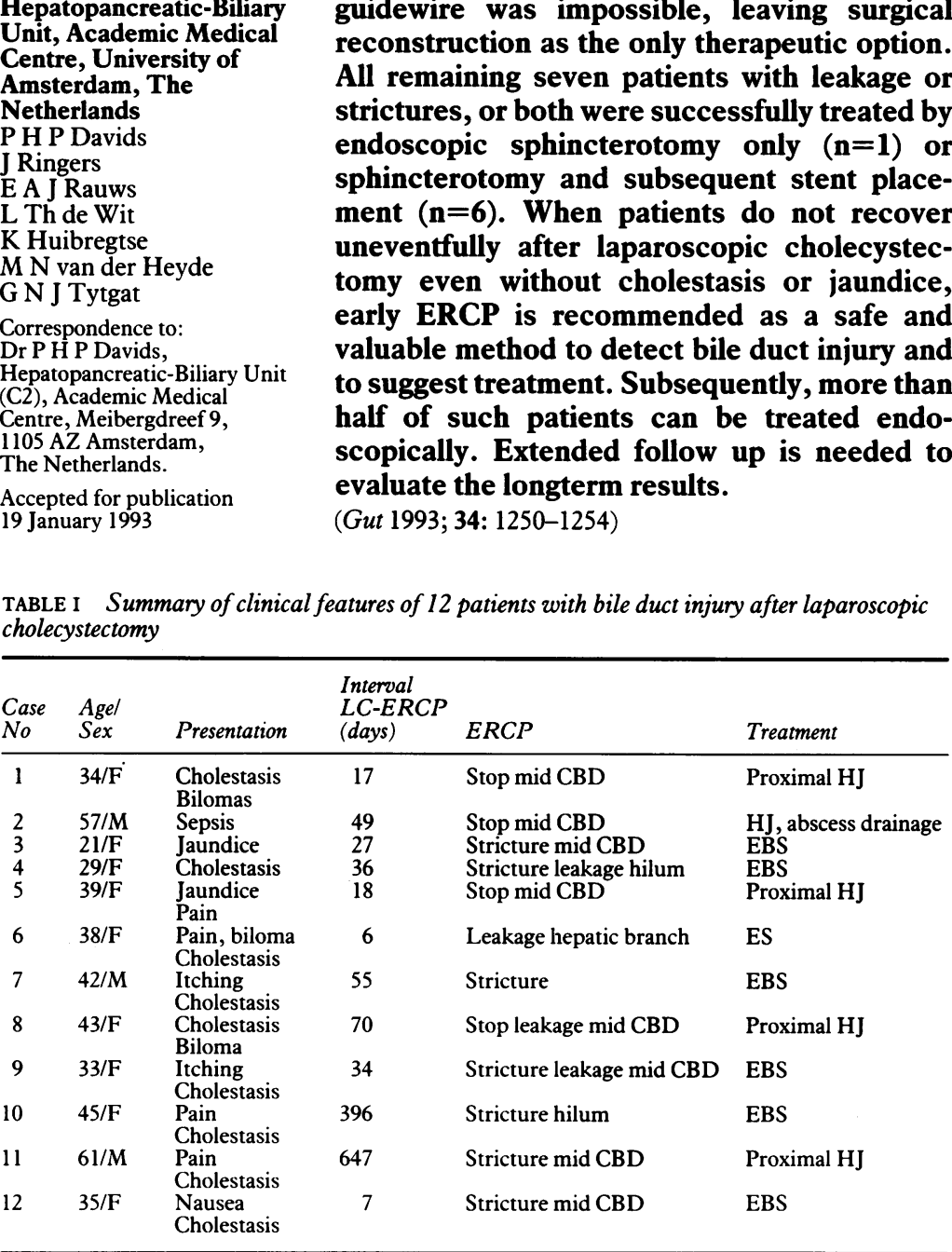

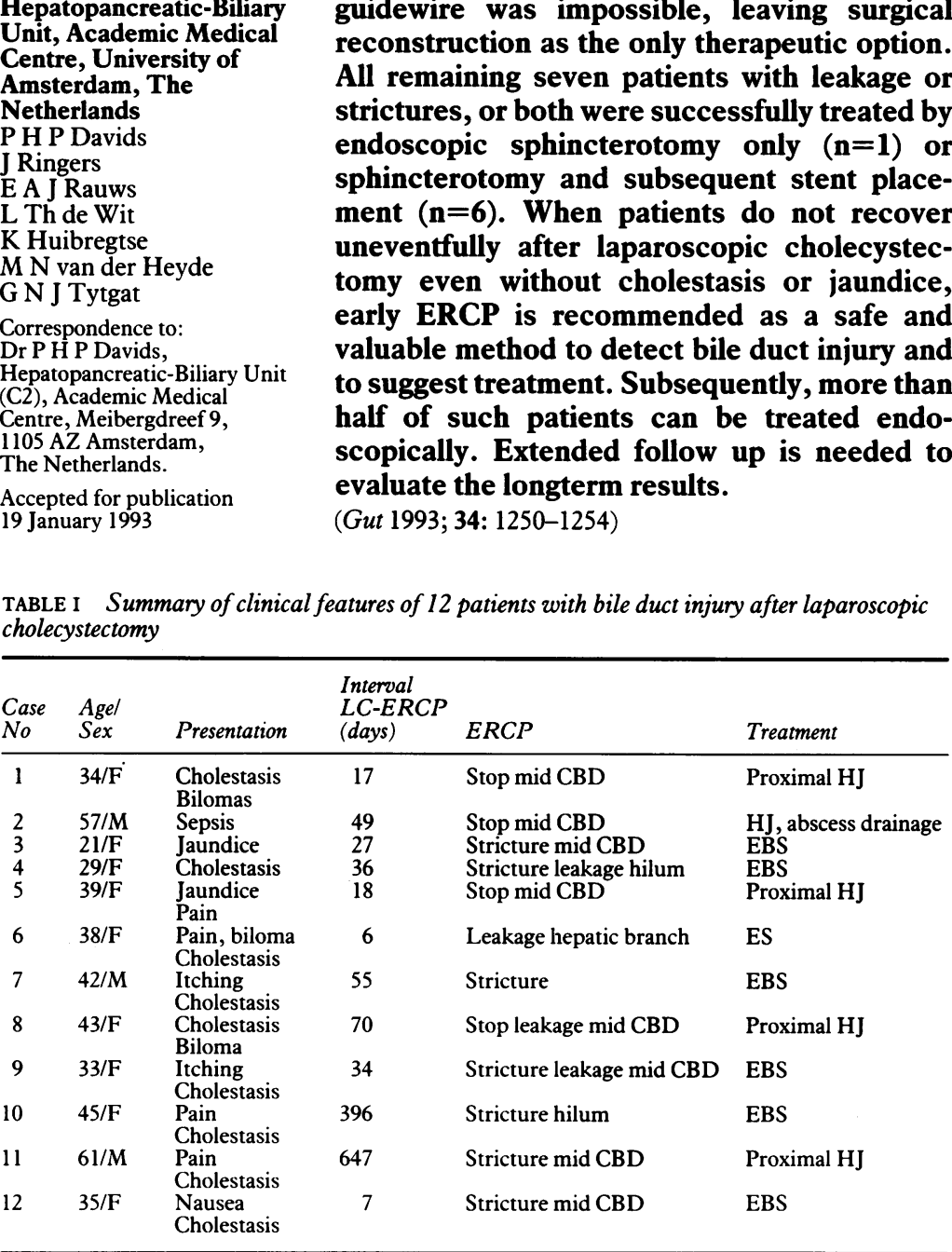

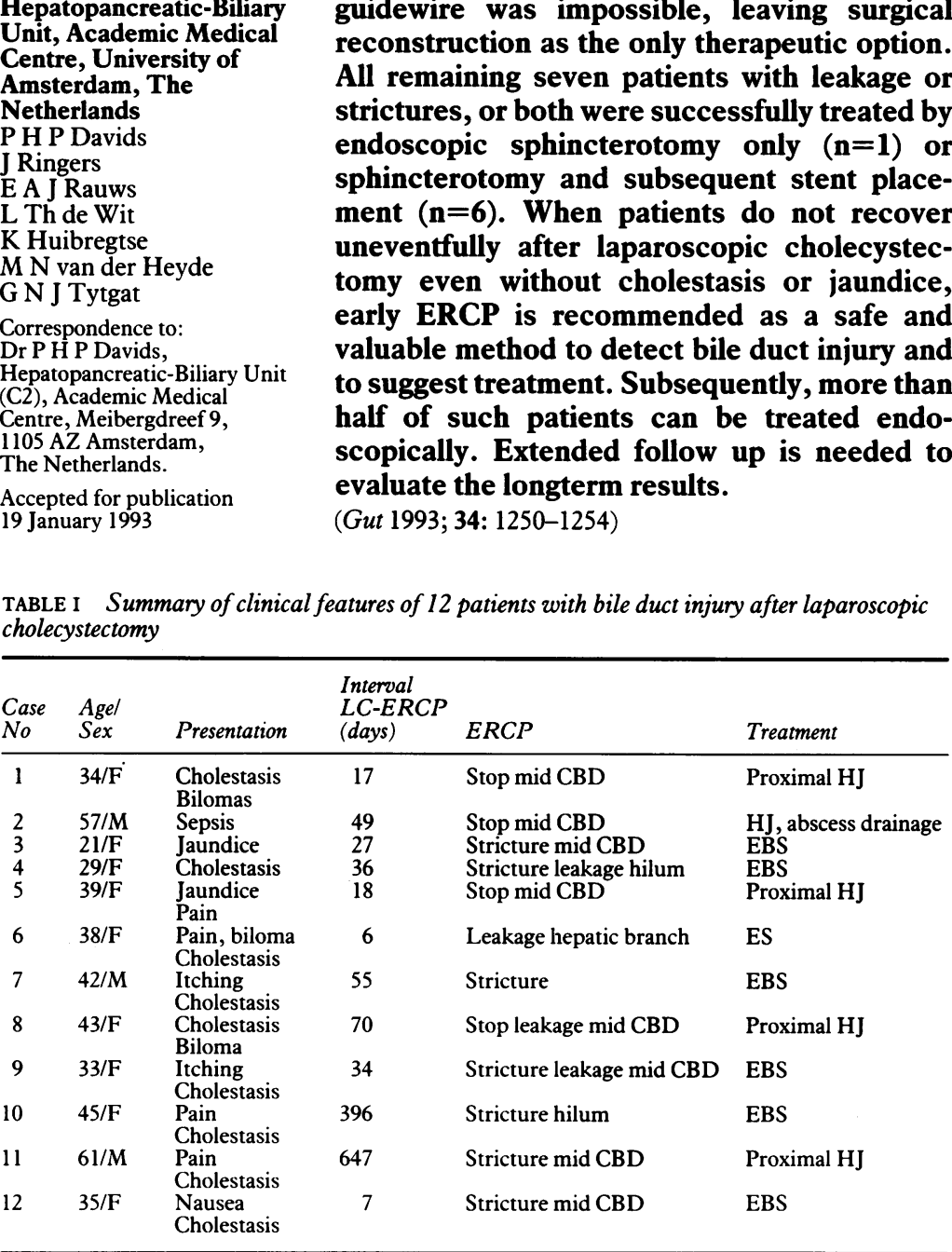

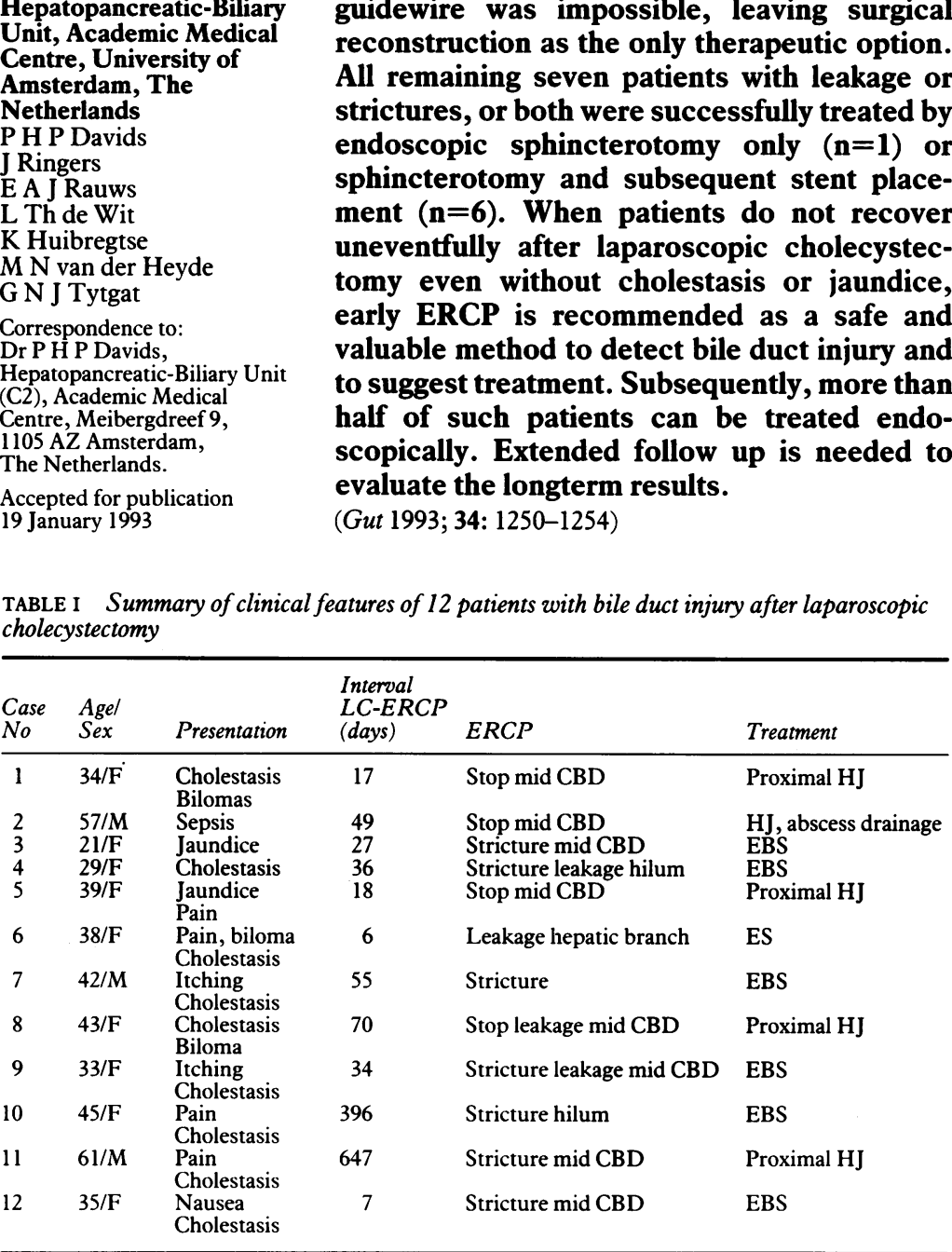

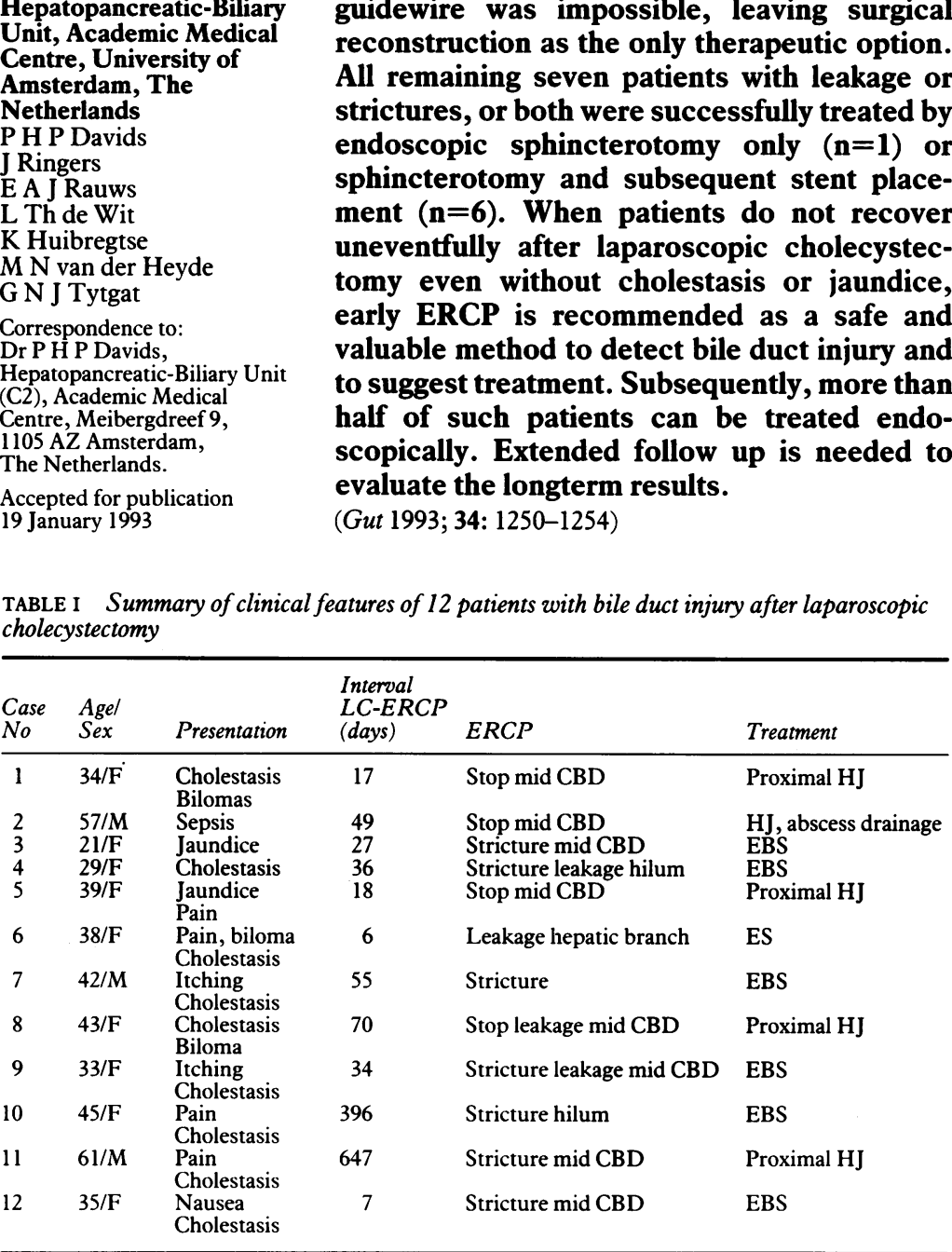

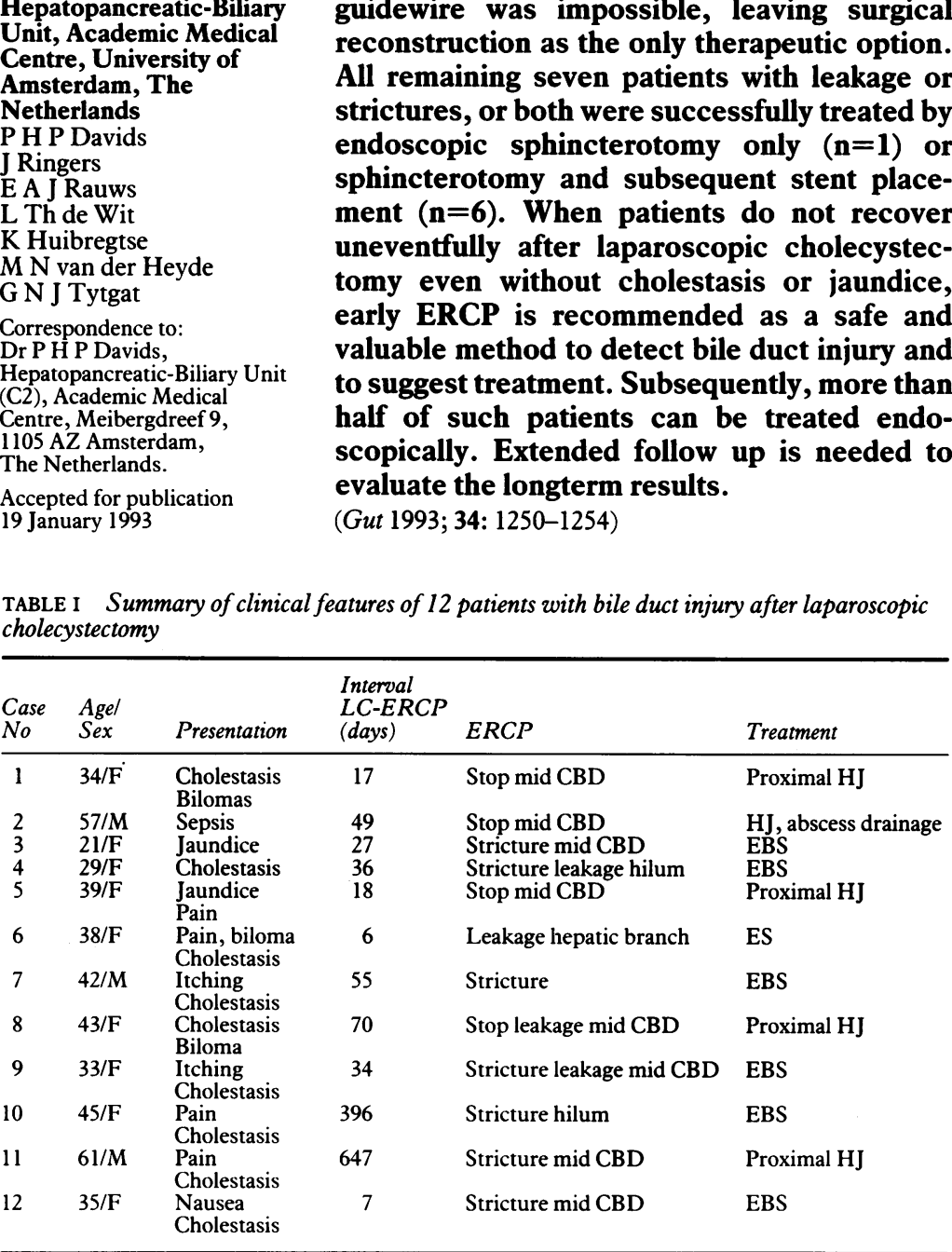

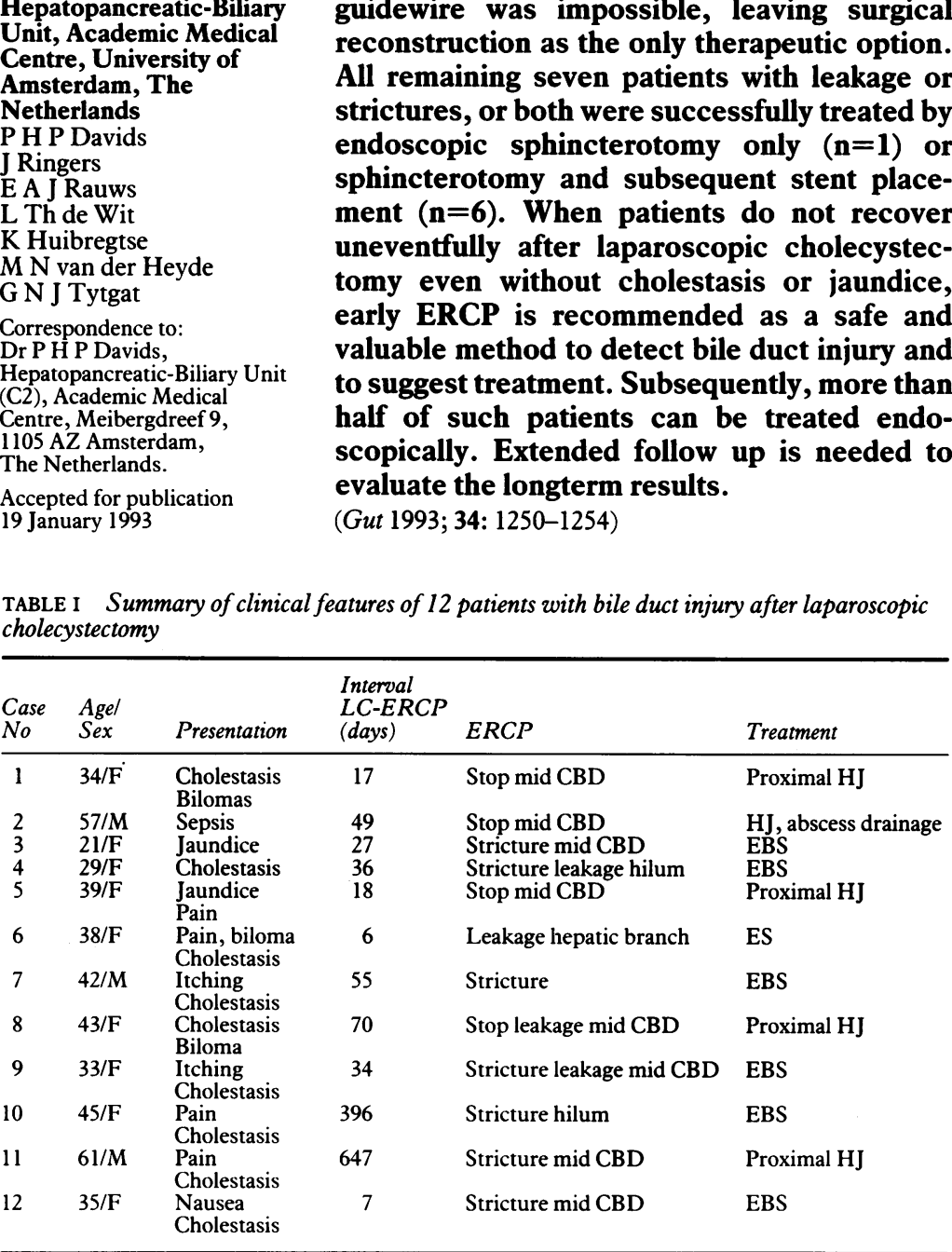

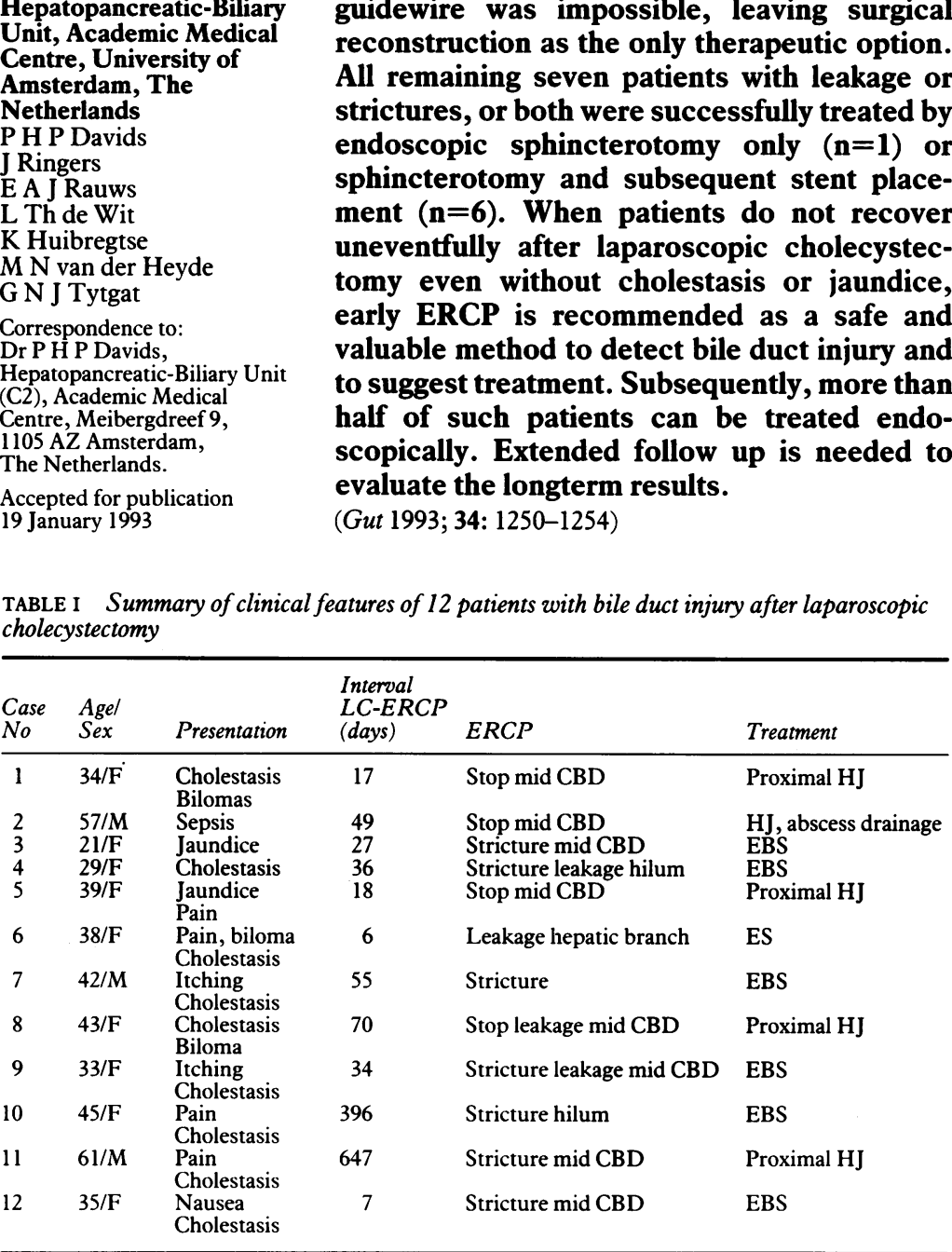

EBS=endoscopic biliary stenting; $E S=$ endoscopic sphincterotomy 
two 10 French gauge $(\mathrm{Fg})$ polyethylene endoprostheses for one year. These stents are electively exchanged every three months to avoid clogging induced cholangitis.

\section{Results}

CASE 1

A 34 year old woman was referred for ERCP, 17 days after laparoscopic removal of a shrunken gall bladder, containing one stone. An operative cholangiogram was not performed. Because of some peroperative bile leakage, a subhepatic drain was positioned and antibiotics were given for five days. Postoperatively, the patient complained of vague abdominal discomfort and the drain was removed after two days. Blood chemistry was monitored regularly, but showed only moderately raised liver enzymes after two weeks. Abdominal ultrasound imaging showed non-dilated bile ducts, several fluid collections, and guided puncture yielded bile. At ERCP a complete stop, resulting from a surgical clip at the level of the cystic duct was visualised. During laparotomy, $2 \mathrm{~cm}$ of more proximal bile duct was missing and bile leaked from the common hepatic duct into the abdominal cavity, explaining the absence of obstructive jaundice. A proximal hepaticojejunostomy with a Roux-en-Y loop reconstruction was performed and the patient was discharged after three weeks.

\section{CASE 2}

A 57 year old man was referred for ERCP, 49 days after laparoscopic removal of a chronically inflamed gall bladder with many adhesions. An operative cholangiogram was not performed. Postoperatively, the subhepatic drain produced $250 \mathrm{ml}$ bile per day. Unfortunately, the patient initially refused to have an ERCP. After accidental drain removal, the abdomen distended rapidly and ultrasound showed the presence of ascites. At relaparotomy a large bile duct defect was seen, located $1.5 \mathrm{~cm}$ proximal to the cystic duct and a Roux-en-Y loop was anastomosed over the perforated area. The patient became septic and was referred to our intensive care unit. Subsequent ERCP showed a total stop at the level of the mid common bile duct (CBD). During the second relaparotomy, multiple abscesses were drained. Eventually, the patient improved and scintigraphy after one month, showed adequate drainage through the jejunal loop.

CASE 3

A 21 year old woman was referred for ERCP, 27 days after laparoscopic cholecystectomy. Peroperative cholangiography showed two clips partially placed over the CBD, which were subsequently removed. Three weeks after this procedure, the patient became jaundiced. Ultrasound did not show dilated intrahepatic bile ducts. At ERCP, a mid CBD stricture at the level of a clip was detected. Only one $11 \mathrm{~cm}, 10 \mathrm{Fg}$ stent could be positioned. The jaundice subsided rapidly and a second stent was inserted after six

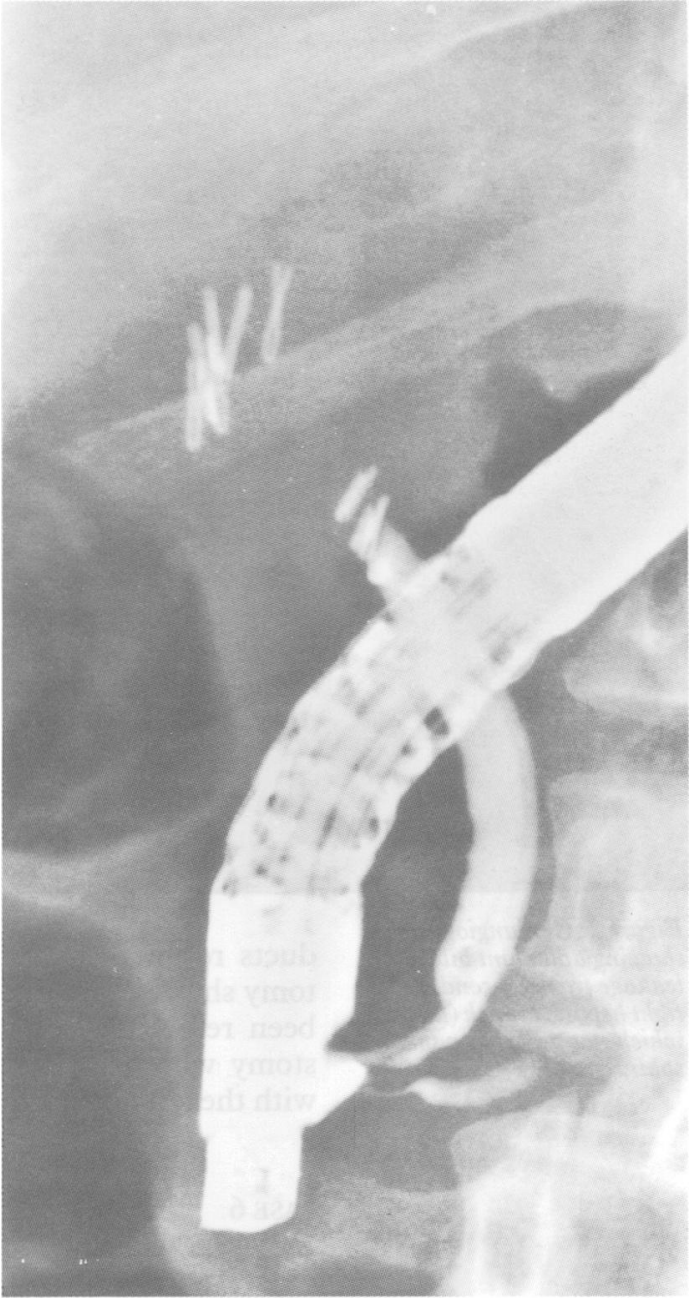

Figure 1: Cholangiogram showing total bile duct obstruction because of transverse clip placement over the common bile duct (Case 5).

weeks, to achieve further stretching of the strictured area.

\section{CASE 4}

A 29 year old woman was referred for ERCP, 36 days after laparoscopic cholecystectomy. Peroperatively, a mid CBD injury was recognised and the procedure was converted to an open cholecystectomy. The defect was sutured over a T-tube. On the third postoperative day, the Ttube was removed after cholangiography showed sufficient drainage. Three weeks after discharge, the patient felt nauseated and blood chemistry showed cholestasis. Subsequent ERCP showed a subhilar stricture and some contrast extravasation. Two $14 \mathrm{~cm}, 10 \mathrm{Fg}$ endoprostheses could be inserted to dilate the stricture. After the procedure the cholestasis subsided.

\section{CASE 5}

A 38 year old woman was referred for ERCP, 18 days after uneventful laparoscopic cholecystectomy. After two weeks she became jaundiced and was referred with the diagnosis of choledocholithiasis. Subsequent ERCP showed a transverse clip over the mid CBD causing a total stop (Fig 1). An attempt to visualise the proximal bile 


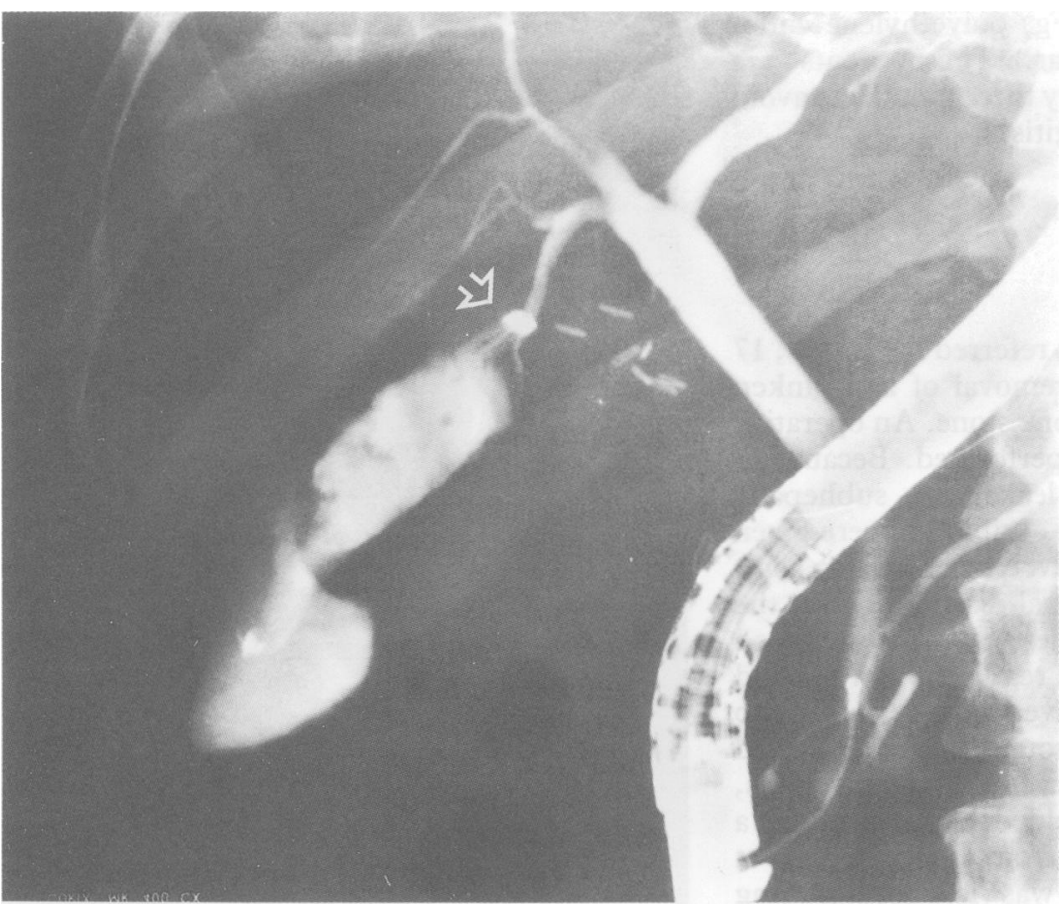

Figure 2: Cholangiogram showing abundant bile leakage from a secondary right hepatic branch (arrow), which stopped after a small sphincterotomy (Case 6). ducts resulted in a small perforation. Laparotomy showed that the common hepatic duct had been resected erroneously. A cholangiojejunostomy with a Roux-en-Y loop was performed, with the left hepatic duct approach.

\section{CASE 6}

A 39 year old woman was referred for ERCP, six days after uneventful laparoscopic cholecystectomy. Postoperatively she complained of abdominal discomfort and blood chemistry showed cholestasis. Ultrasound showed a small subhepatic fluid collection. Subsequent ERCP showed abundant leakage of a hepatic radical and a small sphincterotomy was performed to facilitate bile flow into the duodenum (Fig 2). Possibly a congenital abnormal connection was present between the cystic duct and the right biliary system. The patient improved rapidly and had no complaints one year after this procedure.

\section{CASE 7}

A 42 year old man was referred for ERCP 55 days after a complicated laparoscopic cholecystectomy. Peroperatively bile leakage was encountered and the procedure was converted to a laparotomy. After CBD exploration a T-tube was positioned, which was removed after 10 days. Nearly two months later the patient complained of itching and cholestasis was diagnosed. Abdominal ultrasound showed a stenotic area in the mid CBD, with prestenotic dilation. After failed ERCP elsewhere, ERCP in our centre confirmed the presence of a stricture at the level of a clip. One $14 \mathrm{~cm}, 10 \mathrm{Fg}$, stent was positioned and exchanged for two stents after six weeks.

\section{CASE 8}

A 43 year old woman was referred for ERCP 70 days after uneventful laparoscopic removal of a shrunken gall bladder. Postoperatively, production from the subhepatic drain diminished initially, but after seven days increased to 300 to $500 \mathrm{ml}$ bile per day. Ultrasound showed a non-dilated biliary tree and subhepatic fluid collections. These bilomas were drained percutaneously and several attempts at cannulating the CBD elsewhere were unsuccessful. Subsequent ERCP in our institution showed a complete disconnection at the level of the mid CBD with contrast leakage. Despite the non-dilated biliary tree, a percutaneous transhepatic cholangiogram was feasible: there was no communication between the right and the left system and both branches drained in a subhepatic collection. Laparotomy showed erroneous resection of the total hepatic duct confluence. A double cholangiojejunostomy reconstruction with Roux-en-Y loop was performed with a good result.

CASE 9

A 33 year old obese woman was referred for ERCP 34 days after uneventful laparoscopic removal of a chronically inflamed gall bladder, containing one stone. After three weeks she complained of itching and blood chemistry showed cholestasis. At ERCP a mid CBD stricture was visualised at the level of some clips, with concomitant contrast leakage and an endoprosthesis was inserted. After six weeks, the leakage had stopped and two $10 \mathrm{Fg}$ stents were inserted.

\section{CASE 10}

A 45 year old woman was referred 13 months after laparoscopic cholecystectomy. After five days, an ERCP elsewhere showed bile leakage from the cystic duct stump and a small endoscopic sphincterotomy was performed, followed by stent insertion. The leakage subsided rapidly and after three months the stent was removed. Unfortunately, the patient developed pain and cholestasis and a stenosis at the level of the hilum was diagnosed. Three subsequent balloon dilations were unsuccessful and finally the patient was referred to our institution. During ERCP a firm stricture, of $3 \mathrm{~mm}$ in length, was visualised at the level of several clips and only one $10 \mathrm{Fg}$ endoprosthesis could be inserted initially. After six weeks the stricture was further dilated with two endoprostheses.

\section{CASE 11}

A 61 year old man was referred for ERCP nearly two years after laparoscopic cholecystectomy. After 35 days he became jaundiced. ERCP elsewhere showed a distal obstructing stone, which was successfully removed with a balloon after sphincterotomy. In addition, a small fistulous tract originating from the cystic duct stump was diagnosed. Twenty months later, the patient again complained of pain in the right upper abdomen. Blood chemistry showed recurrent cholestasis. Subsequent ERCP showed a very tight mid $C B D$ stricture at the level of several clips (Fig 3). During two consecutive attempts, passage of a guidewire was impossible. 


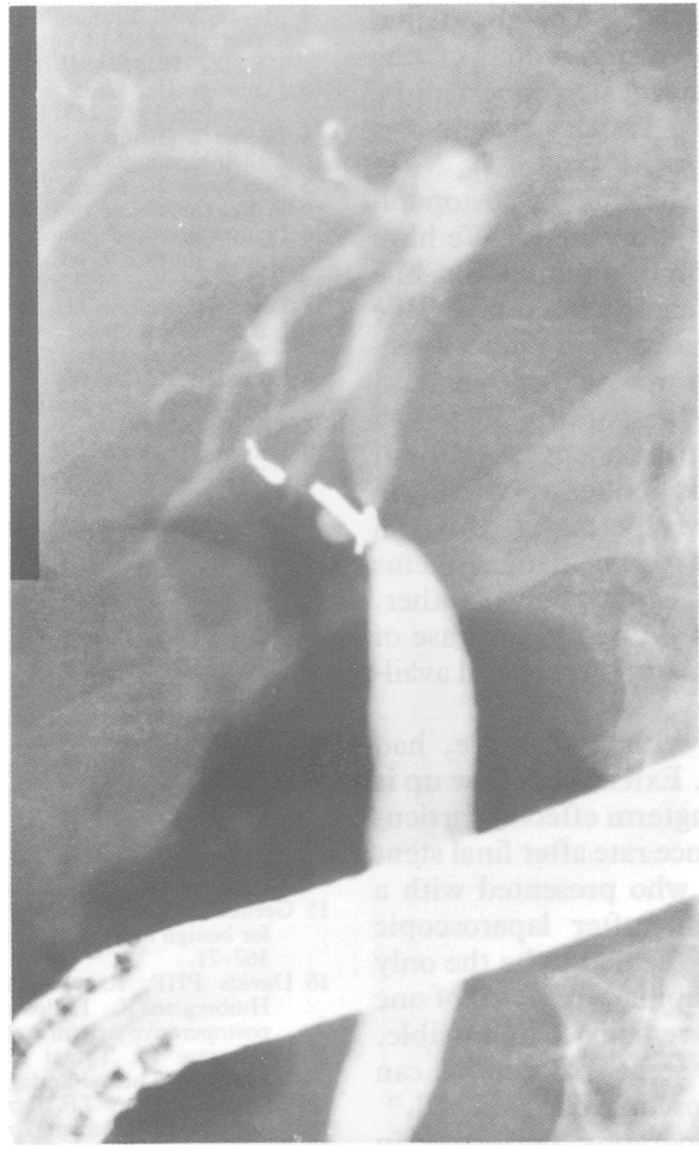

Figure 3: Firm mid common bile duct stricture (arrow), two years after laparoscopic cholecystectomy. Although the proximal biliary tree could be visualised, guidewire passage was impossible during two attempts (Case 11).

After these manipulations, one clip migrated into the CBD and was successfully removed with a Dormia catheter. Later on a hepaticojejunostomy was performed with good result.

CASE 12

A 35 year old woman was referred for ERCP seven days after uneventful laparoscopic cholecystectomy. Three days postoperatively she felt nauseated. Blood chemistry showed cholestatic liver enzymes and ultrasound showed dilated bile ducts. At ERCP a subhilar stricture was visualised with surrouding clips and one $14 \mathrm{~cm}$,

Figure 4: Left: Subhilar stricture because of a clip (arrow). Right: One $10 \mathrm{Fg}$, $14 \mathrm{~cm}$ stent was inserted and exchanged for two stents after six weeks (Case 12).
$10 \mathrm{Fg}$ stent was inserted successfully (Fig 4). A second stent was positioned after six weeks.

\section{Discussion}

In all the 12 patients referred with suspicion of bile duct injury, the biliary tree was successfully visualised during ERCP. This led to a further diagnosis and aided treatment strategy. Remarkably, previous abdominal ultrasound showed non-dilated intrahepatic bile ducts despite the presence of major bile duct injury in four patients.

In general, the clinical presentation of postoperative bile duct injury includes distinct symptoms such as cholestasis, jaundice, persistent bile drainage by drains and sepsis as described after open cholecystectomy. ${ }^{18}$ More important, however, is the occasional presence of an initial relatively symptom free period, which can mislead the clinician. In this study, three patients (cases 1,5 , and 8) with complete bile duct transection had indeed initially little, if any, complaints. This symptom free period lasted for several days and even weeks. After this clinically 'silent' period, the patients eventually developed cholestasis. Surprisingly, subsequent ERCP showed a complete bile duct obstruction. In all three patients, subsequent laparotomy showed a distal CBD occluded by clips and a partially resected common hepatic duct, with free bile leakage into the abdominal cavity. Unhindered bile flow from the liver, may explain this initial 'silent', anicteric period.

According to our experience, the severity of bile duct injuries seems to be changed after laparoscopic cholecystectomy. For the last decade, about one patient a year was referred to our department with a total bile duct transection after open cholecystectomy. ${ }^{16}$ In contrast, after the introduction of the laparoscopic approach, four patients have been referred with total bile duct transections during a one year period. Important factors that may contribute to this apparently increased incidence of major bile duct injuries after laparoscopic cholecystectomy, are absence of three dimensional depth perception during laparoscopy, a changed view on the operative field, and tenting of the common bile duct by anterior traction on the gall bladder to dissect Calot's triangle. ${ }^{19}{ }^{20}$ In general, a large proportion of bile duct injuries can be attributed to the learning experience of the surgeon. ${ }^{2}$

All four patients with complete bile duct transection were treated with a proximal hepaticojejunostomy with Roux-en-Y jejunal loop. When the total common hepatic duct was resected, the left hepatic duct approach was used for the hepaticojejunal anastomosis. ${ }^{21}$ It was difficult to perform a suficiently wide bilioenteric anastomosis in two of four patients, because of a non-dilated biliary tree. Whether this will influence the longterm patency of the anastomosis, remains to be seen.

The treatment of bile leakage after open cholecystectomy, by endoscopic sphincterotomy or stent placement has been reported to yield acceptable results, especially when the patient is referred in an early phase. ${ }^{1322}$ In this study, all three patients with bile leakage were also suc- 
cessfully treated endoscopically. This shows that similar guidelines for decompression of the biliary tree after open cholecystectomy, can be applied after laparoscopic cholecystectomy as well.

The role of endoscopic stenting for postoperative biliary strictures is still debated. ${ }^{23}$ We have advocated initial endoscopic stenting for bile duct strictures after open cholecystectomy. ${ }^{24}$ Bile duct stricturing after laparoscopic cholecystectomy is often due to clip mis or displacement. When these strictures are temporarily dilated by endoscopic stenting, the permanent presence of these clips might perhaps induce restricturing after stent removal. Nevertheless, a proximal hepaticojejunostomy in a young patient seems unattractive and justifies exploration of other, less invasive, alternatives. Moreover, in case of endoscopic failure surgical options are still available.

Six of seven patients with a stricture, had successful stent insertion. Extended follow up is required, to assess the longterm effects, particularly the stricture recurrence rate after final stent removal. In one patient, who presented with a stricture nearly two years after laparoscopic cholecystectomy, surgery seemed to be the only option. Even after transpapillary removal of one clip, guidewire passage remained impossible. Occasionally, however, stent placement can become feasible after endoscopic clip removal. ${ }^{25}$

Intraoperative cholangiography, performed in only one patient in this study, can be helpful in delineating the biliary anatomy to avoid iatrogenic injury. ${ }^{26}{ }^{27}$ Possibly, selected or routine use of intraoperative cholangiography could have prevented or diagnosed some of the injuries.

When bile duct injury is diagnosed, optimal management can only be achieved by a team, including surgeon, endoscopist, and radiologist. ${ }^{28}$ This study has shown that clinicians must be aware of the occasional 'silent' period after major bile duct injuries. Whenever patients do not recover uneventfully after laparoscopic cholecystectomy, early ERCP is a safe and valuable approach to visualise the location and extent of any lesion. More than half of such patients can be treated endoscopically.

1 Dubois F, Berthelot G, Levard H. Cholecystectomy under celioscopy. Ann Chir 1990; 44: 206-15.
2 Meyers WC, Branum GD, Farouk M, et al. A prospective analysis of 1518 laparoscopic cholecystectomies. $N$ Engl f Med 1991; 324: 1073-8.

3 Cameron JL, Gadacz TR. Laparoscopic cholecystectomy. Ann Surg 1991; 213: 1-2.

4 Michie W, Gunn A. Bile duct injuries: a new suggestion for their repair. Brf Surg 1964; 51: 96-100.

5 Rosenqvist H, Myrin SD. Operative injury to the bile ducts. Acta Chir Scand 1960; 119: 92-107.

6 Preoperative and postoperative biliary problems. In: Meyers WC, Jones RS, eds. Textbook of liver and biliary surgery. Philadelphia: J B Lippincott, 1990: 373-90.

7 Peters JH, Ellison EC, Innes JT, et al. Safety and efficacy of laparoscopic cholecystectomy: A prospective analysis of 100 initial patients. Ann Surg 1991; 213: 3-12

8 Cuschieri A, Dubois F, Mouiel J, et al. The European experience with laparoscopic cholecystectomy. Am F Surg 1991; 161: 385-7.

9 Larson GM, Vitale GC, Casey J, et al. Multipractic analysis of laparoscopic cholecystectomy in 1983 patients. Am F Surg 1992; 163: 221-6.

10 Vallon AG, Mason RR, Laurence BM, Cotton PB. Endoscopic retrograde cholangiography in post-operative bile duct strictures. BrF Radiol 1982; 55: 32-5.

11 Del Olmo L, Meroño E, Moreira VF, Garcia T, Garcia-Plaza A. Successful treatment of postoperative external biliary fistulas by endoscopic sphincterotomy. Gastrointest Endosc fistulas by endos

12 Ponchon T, Gallez JF, Valette PJ, Chavaillon A, Bory R. Endoscopic treatment of biliary tract fistulas. Gastrointest Endosc 1989; 35: 490-8

13 Davids PHP, Rauws EAJ, Tytgat GNJ, Huibregtse K. Postoperative bile leakage: Endoscopic management. Gut 1992; 33: 1118-22.

14 Berkelhammer C, Kortan P, Haber GB. Endoscopic biliary prostheses as treatment for benign postoperative bile duct strictures. Gastrointest Endosc 1989; 35: 95-101.

15 Geenen DJ, Geenen JE, Hogan WJ, et al. Endoscopic therapy for benign bile duct strictures. Gastrointest Endosc 1989; 35: 367-71.

16 Davids PHP, Rauws EAJ, Coene PPLO, Tytgat GNJ Huibregtse K. Endoscopic biliary stenting for benign Huibregtse K. Endoscopic biliary stenting for benign
postoperative strictures. Gastrointest Endosc 1992;13:12-8.

postoperative strictures. Gastrointest Endosc 1992; 13: 12-8.
17 Huibregtse K, Tytgat GNJ. Endoscopic biliary drainage. Stuttgart: Thieme Verlag, 1990: 426-38.

18 Collins PG, Goey TF. Iatrogenic biliary stricture: presentation and management. Brf Surg 1984; 71: 900-2.

19 Davidoff AM, Pappas TN, Murray EA, et al. Mechanisms of major biliary injury during laparoscopic cholecystectomy. Ann Surg 1992; 215: 196-202.

20 Wolfe BM, Gardiner BN, Leary BF, Frey CF. Endoscopic cholecystectomy. An analysis of complications. Arch Surg 1991; 126: 1192-8.

21 Blumgart LH, Kelley CJ. Hepaticojejunostomy in benign and malignant biliary stricture: approaches to the left hepatic malignant biliary stricture: approach
ducts. Br $\mathcal{F}$ Surg 1984; $71: 257-61$.

22 Kozarek RA, Traverso LW. Endoscopic stent placement for cystic duct leak after laparoscopic cholecystectomy. Gastrointest Endose 1991; 37: 71-3.

23 Cotton PB, Baillie J, Pappas TN, Meyers WS. Laparoscopic cholecystectomy and the biliary endoscopist. Gastrointest Endosc 1991; 37: 94-7.

24 Davids PHP, Tanka AJF, Rauws EAJ, et al. Benign biliary strictures: Surgery or Endoscopy? Ann Surg 1993; 217: 237-43.

25 Weber J, Adamek HE, Riemann JF. Endoscopic stent placement and clip removal for common bile duct stricture after laparoscopic cholecytectomy. Gastrointest Endosc 1992; 38: $181-2$

26 Berci GB, Sackier JM, Paz-Partlow M. Routine or selected intraoperative cholangiography during laparoscopic cholecystectomy? Am $\mathcal{F}$ Surg 1991; 161: 355-60.

27 Flowers JL, Zucker KA, Graham SM, Scovill WA, Imbembo AL, Bailey RW. Laparoscopic cholangiography - Results and indications. Ann Surg 1992; 215: 209-15.

28 Liguory C, Vitale GC. Biliary perestroika. Am 7 Surg 1990; 160: $237-8$. 